ISSN 0258-7122

Bangladesh J. Agril. Res. 33(3) : 607-616, December 2008

\title{
STUDY ON GENETIC DIVERSITY OF POINTED GOURD USING MORPHOLOGICAL CHARACTERS
}

\author{
A.S.M.R. KHAN ${ }^{1}$, M.G. RABBANI ${ }^{2}$, M.A. SIDDIQUE ${ }^{3}$ AND M.I. HOSSAIN ${ }^{4}$
}

\begin{abstract}
The genetic diversity among 64 pointed gourd genotypes were assessed through multivariate analysis from an experiment conducted in Regional Agricultural Research Station, lshurdi, Pabna during the growing season 2002-2003. The genotypes were grouped into twelve clusters. The cluster $\mathrm{V}$ consisted of highest number of genotypes and it was nine, the cluster VI and cluster VIII contained the lowest number of genotypes and it was two in each. The clustering pattern of the genotypes under this study revealed that the genotypes collected from the same location were grouped into different clusters. The genotypes of Jessore were distributed in different clusters. The highest inter genotype distance as 366.3 observed between the genotypes P0022 and P0007 and the lowest 2.6 as observed between the genotypes P0043 and P0044. Cluster V had the highest cluster mean value for internode length, fruit weight per plant and yield the highest inter-cluster distance was noticed between cluster III and II (45.71) and the lowest between cluster VII and VI (3.33). 'The highest intra cluster distance was computed for cluster III and that was lowest for the cluster II. The first five axes accounted for $77.65 \%$ of the total variation among the 13 characters describing 64 pointed gourd genotypes. Fruit weight, seeds per fruit and fruit weight per plant contributed maximum to the total divergence. The results obtained by $\mathrm{D}^{2}$ analysis were confirmed by canonical analysis.
\end{abstract}

Key Words: Diversity pointed gourd, morphological characters.

\section{Introduction}

As a dioecious crop, pointed gourd has high cross-pollination mechanism. Due to its out crossing characteristics, variability is always generating in this crop. Quantification of such variability from genetic point of view is very scanty that the first axis largely accounted for the variation among the genotype (28.66) followed by second axis (16.53). The first five axes for accounted $77.65 \%$ of the total variation among the 13 characters describing 64 pointed gourd genotypes while the former two accounted for $45.19 \%$. These results are in agreement with the findings of Ram (2001)

${ }^{1}$ Senior Scientific Officer (Biotechnology), BARI, Joydebpur, Gazipur, ${ }^{2 \& 3}$ Professor, Department of Horticulture, BAU, Mymensingh, ${ }^{4}$ Scientific Officer (Economics), BARI, .Joydebpur, Gazipur, Bangladesh. 
Table 1. Latent roots (Eigen values) and percent of variation in respect of 13 characters in pointed gourd.

\begin{tabular}{l|l|l|c}
\hline $\begin{array}{c}\text { Principal } \\
\text { component axis }\end{array}$ & Latent roots & $\begin{array}{c}\text { \% of total variation } \\
\text { accounted for }\end{array}$ & $\begin{array}{c}\text { Cumulative } \\
\text { percent }\end{array}$ \\
\hline I & 3.725 & 28.66 & 28.66 \\
II & 2.149 & 16.53 & 45.19 \\
III & 1.705 & 13.12 & $50: 31$ \\
IV & 1.535 & 11.81 & 70.12 \\
V & 0.978 & 7.53 & 77.65 \\
VI & 0.817 & 6.28 & 83.93 \\
VII & 0.689 & 5.28 & 89.21 \\
BIII & 0.566 & 4.36 & 93.57 \\
IX & 0269 & 2.07 & 95.64 \\
X & 0.243 & 1.88 & 97.52 \\
XI & 0.187 & 1.45 & 98.97 \\
XII & 0.088 & 0.68 & 99.65 \\
XIII & 0.045 & 0.35 & 100.00 \\
\hline
\end{tabular}

\section{Construction of scattcr diagram}

On the basis of principal axes I and II from the principal component analysis, a two way dimensional scatter diagram $\left(\mathrm{Z}_{1} \mathrm{Z}_{2}\right)$ using component score I as $\mathrm{X}$-axis and component score 2 as $\mathrm{Y}$-axis was constructed, which is presented in Figure 1. The distribution of genotypes in scattered diagram (Fig. 1 and Fig. 2) was apparently distributed into 12 groups, which revealed that there exists considerable diversity among the genotypes.

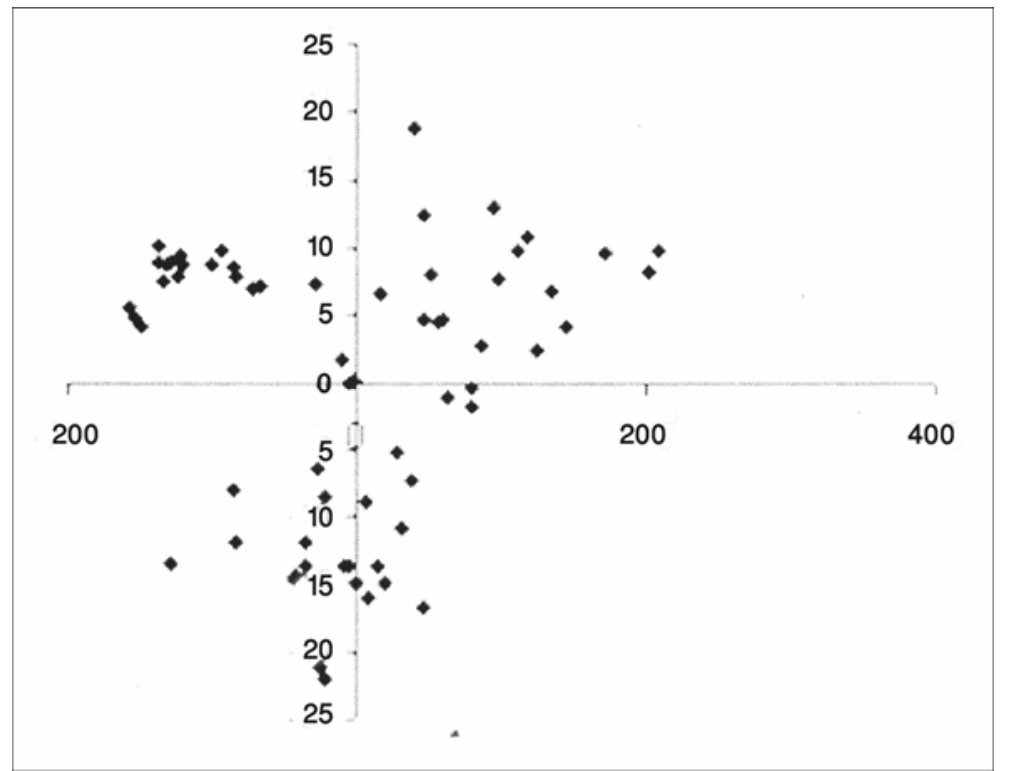

Fig 1. Scattered diagrams of 64 pointed gourd genotypes based on their principal Component scores 


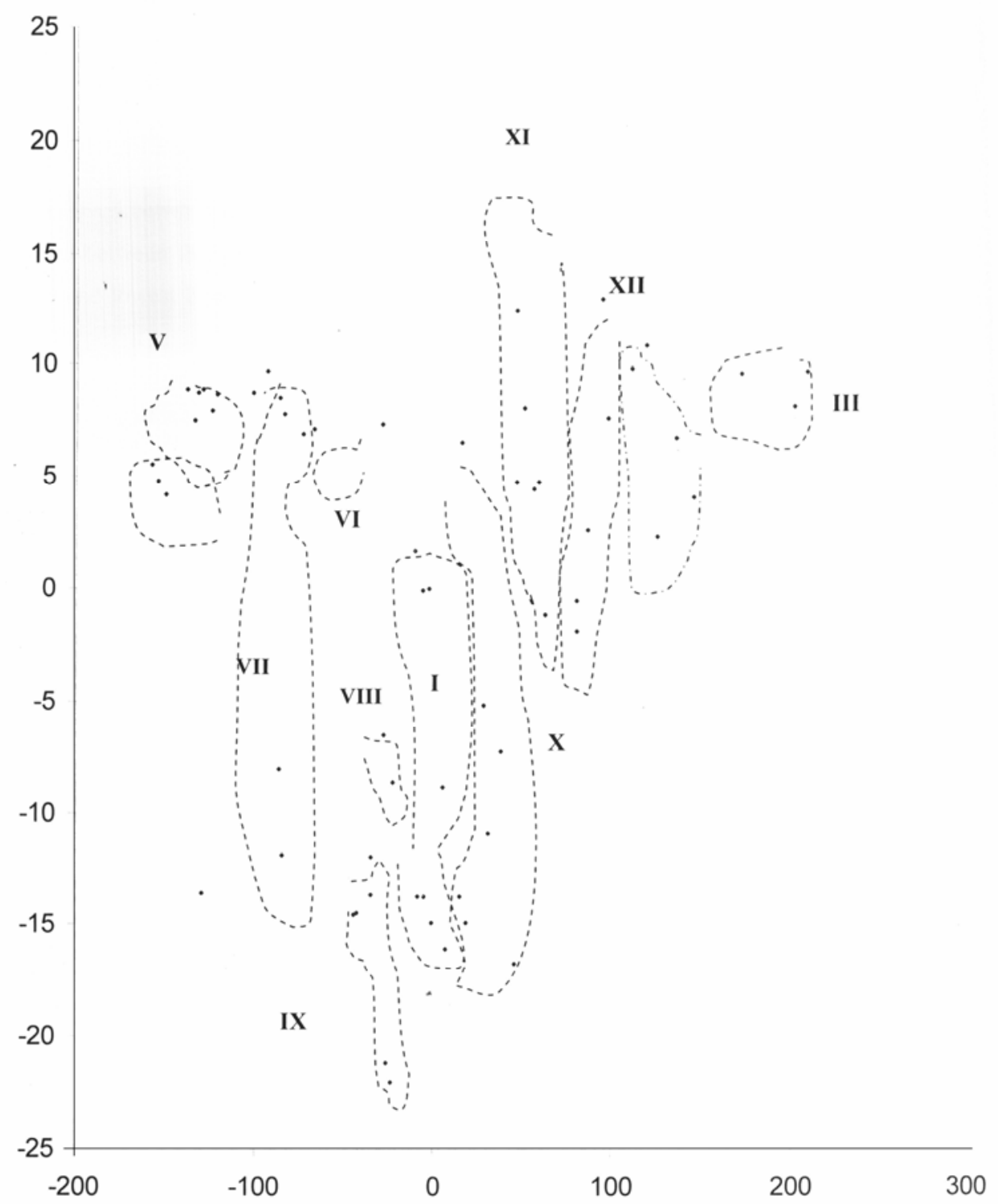

Fig 2. Scattered diagram of 64 pointed gourd genotypes based on their prinpal component sco superimposed with clustering. 


\section{Principal Coordinate Analysis (PCO)}

Inter genotypic distance $\mathrm{D}^{2}$ were obtained from principal coordinate analysis for all possible combinations between pairs of genotypes. The highest inter genotype distance was 366.3 observed between the genotypes PG022 and PG007 followed by the distance 362.9 observed between the genotypes PG022 and PG013. The lowest distance was 2.6. which was observed between the genotypes PG043 and PG044 followed by the distance 3.0 was observed between the genotypes PGI4 and PG0I5 (Table 2). The difference between the highest and lowest intergenotype distance indicated the presence of variability among the 64 genotypes of pointed gourd.

Table 2 Ten of each lower and higher Inter- genotypes distances between pairs of genotypes.

\begin{tabular}{l|l|l|l}
\hline $\begin{array}{c}10 \text { lower } \mathrm{D}^{2} \\
\text { values }\end{array}$ & \multicolumn{1}{c|}{$\begin{array}{c}\text { Genotypes } \\
\text { combination }\end{array}$} & 10 higher $\mathrm{D}^{2}$ values & \multicolumn{1}{c}{$\begin{array}{c}\text { Genotypes } \\
\text { combination }\end{array}$} \\
\hline 2.6 & $43 \times 44$ & 366.3 & $22 \times 7$ \\
3.0 & $14 \times 15$ & 362.9 & $22 \times 12$ \\
3.1 & $27 \times 31$ & 359.7 & $27 \times 18$ \\
3.2 & $25 \times 31$ & 359.0 & $22 \times 12$ \\
3.5 & $40 \times 42$ & 352.5 & $12 \times 18$ \\
3.7 & $28 \times 33$ & 347.0 & $22 \times 30$ \\
3.9 & $57 \times 61$ & 343.2 & $22 \times 27$ \\
4.1 & $7 \times 13$ & 341.2 & $22 \times 31$ \\
4.2 & $30 \times 37$ & 340.7 & $18 \times 30$ \\
4.3 & $10 \times 6$ & 338.3 & $25 \times 2$ \\
\hline
\end{tabular}

The $1 \mathrm{~mm}$ cluster distance was computed by using the values of inter accession distance from distance matrix according to Singh and Chaudhary (1985). The magnitudes of the intra cluster distances were not always proportional to the number of genotypes in the clusters (Table 4). In the study, it was observed that although the cluster composed of the highcst number of genotypes nine (Tables 5) but its hjtra-cluster distance was not necessarily the highest. Statistical distances represent the index of genetic diversity among the clusters. The highest infl cluster distance was computed for cluster III (28.96) composed of three genotypes followed by cluster IV (24.69), cluster XII (21.0). cluster X (20.02). cluster Xl (17.45), cluster 1(15.83) and cluster VIII (15.0). The minimum intra cluster distance sa.s lound in cluster 11(5.63). The intra cluster distance of cluster V. cluster VI. cluster VII. and cluster IX were 14.45, 14.0, 13.2 and 12.9 consisting of9, 2, 6 and 6 genotypes, respectively. 


\section{Canonical Variant Analysis (CVA)}

Canonical variant analysis was performed to obtain the cluster distance (Mahalanohis's $\mathrm{D}^{2}$ value). The values of inter cluster distance $\left(\mathrm{D}^{2}\right)$ are presented in Table 3. Statistical distances represent the index of genetic diversity among the clusters. The inter cluster distances were larger than the intra cluster distances suggesting wider genetic diversity aniong the genotypes of different groups (Table 3).

Based on the thirteen quantitative characters of pointed gourd genotypes, PCO was carried out to determine inter accession distance $\left(\mathrm{D}^{2}\right)$. The intracluster distance, obtained by using the values of inter genotypes distance under each cluster as suggested by Singh and Chaudhuary (1985), and intra cluster distance was obtained from CVA are presented in Table 4.

Table 3 Average inter and intra- cluster distance (D2) for 64 pointed gourd genotypes.

\begin{tabular}{l|c|c|c|c|c|c|c|c|c|c|c|c}
\hline Cluster & I & II & III & IV & V & VI & VII & VIII & IX & X & XI & XII \\
\hline I & $\mathbf{1 5 . 8 3}$ & & & & & & & & & & & \\
II & 19.96 & $\mathbf{5 . 6 3}$ & & & & & & & & & & \\
III & 26.68 & 45.71 & $\mathbf{2 8 . 9 6}$ & & & & & & & & & \\
IV & 18.43 & 37.75 & 9.16 & $\mathbf{2 4 . 6 9}$ & & & & & & & & \\
V & 17.13 & 6.81 & 43.02 & 34.69 & $\mathbf{1 4 . 4 5}$ & & & & & & & \\
VI & 6.73 & 12.73 & 34.42 & 25.99 & 9.18 & $\mathbf{1 4 . 0}$ & & & & & & \\
VII & 10.93 & 9.81 & 34.92 & 28.62 & 6.97 & 3.33 & $\mathbf{1 2 . 9 0}$ & & & & & \\
VIII & 5.51 & 18.97 & 28.70 & 20.16 & 15.51 & 7.17 & 9.77 & $\mathbf{1 5 . 0}$ & & & & \\
IX & 5.41 & 16.43 & 31.23 & 22.89 & 12.78 & 5.23 & 7.48 & 5.31 & $\mathbf{1 3 . 2}$ & & & \\
X & 5.90 & 23.42 & 23.01 & 14.89 & 20.50 & 12.07 & 14.46 & 7.43 & 8.60 & $\mathbf{2 0 . 0 2}$ & & \\
XI & 8.18 & 27.18 & 19.31 & 11.05 & 24.17 & 15.77 & 18.18 & 10.38 & 12.69 & 4.90 & $\mathbf{1 7 . 4 5}$ & \\
XII & 12.48 & 32.09 & 14.87 & 6.83 & 29.04 & 20.34 & 22.93 & 14.74 & 17.04 & 8.50 & 5.86 & $\mathbf{2 1 . 0}$ \\
\hline
\end{tabular}

The cluster Ill and II were more diverse as indicated by maximum inter cluster distances between them (45.71) followed by the distance between clusters $\mathrm{V}$ and III (43.02). IV and II (37.75), VII and III (36.92), V and IV (34.69), IV and III (34.72) XII and II (32.09) and between IX and III (3 I .23). The maximum values of inter cluster distance indicated that the genotypes belonging to cluster III were far away from those of cluster II. Sirnilarly, the higher inter cluster values between cluster V and Ill. IV and II. VII and Ill. V and IV, IV and Ill, XII and II and IX and III indicated that the genotypes belonging to each pair of cluster were far diverse. The minimum inter cluster divergence was observed between cluster VII and VI (3.33) indicating that the genotype of these cluster were genetically 
closed. Higher inter and intra-cluster distances indicate higher genetic variability among genotypes between and within clusters, respectively. The minimum inter and intra-eluster distance indicates closeness among the genotypes of two clusters and within the cluster also. These relationships were also reflected in the scatter diagram (Fig. 1). The cluster means of nine characters for 64 genotypes are given in Table 4. I)ifference in clusters means existed for almost all the characters.

\section{Non-hierarchical clustering}

None hierarchical clustering using co-variance matrix grouped 64-pointed gourd genotypes into twelve different clusters (Table 5). It may be concluded that these results were confirmatory with the clustering pattern of the genotypes obtained through principal component analysis. Ram (2001) carried out component analysis and cluster analysis in (7) pointed gourd genotypes, and all genotypes got disbursed into 8 groups in the present study. Cluster V contained the highest number of genotypes (9) followed by cluster 1 (8). cluster $X$ (7), cluster IX (7), cluster X (6), cluster VII (6) and cluster IV (5), respectively. While cluster II. III. and VIII and cluster VI having three and two genotypes, respectively. The clustering pattern of the genotypes under this study revealed that the genotypes collected from the same location can also group into different clusters. The genotypes of Jessore were distributed in different clusters. The genotypes belonging to different locations were grouped in the same cluster (Table 5). This shows that geographic diversity was not related to genetic diversity of these materials. Masud el al. (1995) also reported similar results in sweet gourd.

\section{Contribution of different characters towards divergence}

The contribution of the thirteen characters towards divergence is presented in Table 6. The results of CVA revealed that in vector I (Z), the important characters responsible for genetic divergence in the major axis of differentiation were female flower length, node order, fruit weight, seeds per fruit, dry matter and fruits weight per plant (Table 6$)$. In vector $11\left(\mathrm{Z}_{2}\right)$, days to first flowering, node order, fruit weight. seeds per fruit, pulp seed ratio, and fruits weight per plant played a major role, while rest of the characters played a minor role in the second axis of differentiation. The role of single fruit weight, seeds per fruit and fruits weight per plant in both the vectors indicated the important component of genetic divergence among the 64 pointed gourd genotypes. Besides these, days to flowering, female flower length. node order, pulp seed ratio and dry matter percentage contributed considerably towards divergence. Negative values in both the vectors for internode length, fruit length and fruit width indicated that had the 


Table 4 Cluster mean values for yield and yield contributing characters of pointed gourd and number of genotypes in
each cluster.
\begin{tabular}{lllll|l|l|l|l|l|l|l|l|l}
\hline \\
Characters & I & II & III & IV & V & VI & VII & VIII & IX & X & XI & XII \\
\hline Days to $1^{\text {st flowering }}$ & 81.87 & 81.23 & 85.75 & 96.86 & 92.00 & 94.00 & 88.83 & 86.33 & 81.17 & 80.39 & 87.14 & 84.62 \\
Female flower length (cm) & 5.91 & 6.36 & 5.39 & 5.2 & 6.30 & 6.45 & 6.30 & 6.41 & 5.80 & 6.11 & 6.06 & 6.40 \\
Node order at 1 $1^{\text {st flowering }}$ & 10.41 & 10.33 & 8.90 & 9.29 & 8.70 & 10.00 & 10.33 & 7.67 & 8.50 & 7.13 & 8.147 & 9.50 \\
Internode length (cm) & 8.07 & 7.95 & 6.97 & 8.24 & 10.21 & 8.82 & 7.85 & 10.32 & 9.39 & 8.71 & 9.90 & 9.43 \\
Fruit weight (g) & 52.59 & 45.12 & 35.89 & 35.53 & 46.76 & 44.72 & 47.49 & 49.01 & 61.30 & 51.09 & 36.98 & 41.47 \\
Frit width (cm) & 3.61 & 3.36 & 3.33 & 3.47 & 3.86 & 3.54 & 3.59 & 3.62 & 3.76 & 3.69 & 3.48 & 3.52 \\
Fruit length (cm) & 10.75 & 10.35 & 10.40 & 10.58 & 9.76 & 10.09 & 10.38 & 9.93 & 10.40 & 11.27 & 1091 & 10.54 \\
Seeds/ fruit & 23.89 & 32.44 & 25.31 & 22.21 & 19.36 & 23.66 & 26.97 & 25.01 & 21.84 & 24.28 & 20.71 & 19.64 \\
Pulp: Seed & 15.32 & 9.37 & 13.88 & 12.49 & 13.88 & 12.82 & 13.64 & 11.98 & 18.03 & 14.62 & 13.76 & 14.89 \\
Dry mater (\%) & 7.08 & 6.85 & 6.55 & 7.21 & 7.00 & 6.87 & 7.22 & 7.90 & 6.91 & 6.93 & 7.57 & 6.92 \\
Fruits wt./ plant (kg) & 9.47 & 11.00 & 1.72 & 5.14 & 12.51 & 11.67 & 11.31 & 11.49 & 12.42 & 8.70 & 6.04 & 6.68 \\
Yield (t/ha) & 28.47 & 33.08 & 11.24 & 15.56 & 37.45 & 32.32 & 33.86 & 31.48 & 36.13 & 26.37 & 18.19 & 19.98 \\
Number of genotypes & 8 & 3 & 3 & 5 & 9 & 2 & 6 & 3 & 6 & 7 & 7 & 5 \\
\hline
\end{tabular}


Table 5. Distribution of 64 pointed gourd genotypes in 12 clusters.

\begin{tabular}{|c|c|c|c|}
\hline $\begin{array}{c}\text { Cluster } \\
\text { no. }\end{array}$ & $\begin{array}{l}\text { Total no. of } \\
\text { genotypes } \\
\text { in cluster }\end{array}$ & $\begin{array}{l}\text { Genotypes included in different } \\
\text { clusters }\end{array}$ & $\begin{array}{l}\text { Place of } \\
\text { collection }\end{array}$ \\
\hline \multirow[t]{3}{*}{ I } & \multirow[t]{3}{*}{8} & PG029 & Meherpur \\
\hline & & $\begin{array}{llll}\text { PG048, PG050 PG052 } & \text { and } \\
\text { PG54 } & & & \\
\end{array}$ & Gaibandha \\
\hline & & PG06, PG00 and PG011 & Pabna \\
\hline II & 3 & PG07, PG02, and PG013 & Kushtia \\
\hline III & 3 & PG08, PG01 and PG 02 & Rangpur \\
\hline \multirow[t]{3}{*}{ IV } & \multirow[t]{3}{*}{5} & PG03 & Natore \\
\hline & & PG016, PG053 & Bogra \\
\hline & & PG03 and PG04 & Rajshah \\
\hline V & 9 & $\begin{array}{l}\text { PG025, PG026, PG027, PG028, } \\
\text { PG030, PG31, PG033, PG037, } \\
\text { and PG042 }\end{array}$ & Jessore \\
\hline \multirow[t]{2}{*}{ VI } & \multirow[t]{2}{*}{2} & PG03 & Kushtia \\
\hline & & PG05 & Jessore \\
\hline VII & 2 & $\begin{array}{l}\text { PG005, PG006, PG009, PG004 } \\
\text { and PG015 }\end{array}$ & Kushtia \\
\hline \multirow[t]{2}{*}{ VIII } & \multirow[t]{2}{*}{3} & PG034 and PG036 & Pabna \\
\hline & & PG039 & Jessore \\
\hline IX & 6 & $\begin{array}{l}\text { PG040, PG041, PG043, PG044, } \\
\text { PG045 and PG046 }\end{array}$ & Jessore \\
\hline \multirow[t]{5}{*}{$\mathrm{X}$} & \multirow[t]{5}{*}{7} & PG001 & Rangpur \\
\hline & & PG04 & Pabna \\
\hline & & PG07, PG049 and PG051 & Gaibandha \\
\hline & & PG061 & Rajshah \\
\hline & & PG06 & Chuadanga \\
\hline \multirow[t]{3}{*}{$\mathrm{XI}$} & \multirow[t]{3}{*}{7} & PG02, PG038 & Bogra \\
\hline & & PG05 & Rangpur \\
\hline & & PG07 & Chuadanga \\
\hline \multirow[t]{2}{*}{ XII } & \multirow[t]{2}{*}{5} & PG00, PG00 and PG017 & Rangpur \\
\hline & & PG020 and PG058 & Natore \\
\hline
\end{tabular}

lowest contribution to the total divergence. Hence, considerable emphasis should be given on single fruit weight, seeds per fruit and fruit weight per plant to increase fruit yield in pointed gourd. Mathex et al. (1986) reported that fruit weight per plant was the major contributor towards divergence in Cucumis melo. Masud et al. (1995) found that fruits weight was one of the important contributors to genetic divergence in sweet gourd. 
Table 6. Relative contribution of different characters towards divergence.

\begin{tabular}{l|l|l}
\hline \multicolumn{1}{c}{ Characters } & \multicolumn{1}{c}{ Vector I } & \multicolumn{1}{c}{ Vector II } \\
\hline Days to 1t flowering & -0.0713 & 0.0068 \\
Female flower length (crn) & -1.2057 & -0.5659 \\
Node order at 1st flowering & 0.1952 & 0.0394 \\
Internode length (cm) & -0.2036 & -0.5172 \\
Fruit weight (g) & 0.0100 & 0.0353 \\
Fruit length (cm) & -0.1525 & -0.6790 \\
Fruit width (cm) & -0.6464 & -0.3479 \\
Seeds/fruit & 0.0419 & 0.0854 \\
Pulp : Seed & -0.020 & 0.13182 \\
Dry mater (\%) & -0.0297 & 1.3182 \\
Fruits/plant & -0.1172 & -0.0294 \\
Fruits wt./plant (kg) & 0.1487 & 1.6650 \\
Yield (t/ha) & -0.0957 & -0.2561 \\
\hline
\end{tabular}

\section{Selection of genotypes for future improvement}

Considering the magnitude of genetic distance, contribution of different characters towards the total divergence and magnitude of cluster means for different characters performance, the following genotypes were considered to perform better if used in hybridization programme. The genotypes PGOOI of cluster X could be selected for earliness and longer fruit. The genotypes PG023, PG029 and PG042 of the cluster $\mathrm{V}$ could he selected for lower seed, higher fruit weight per plant and yield. The genotypes PGOO7, PGOI2 and PCOI3 of the cluster II could be selected for higher number of fruits per plant. The genotypes PG043. PG044 PG045 and PG046 of the cluster IX could he selected for size and width of fruit.

Table 7. Finally selected genotypes against important traits.

\begin{tabular}{|l|l|l|l|l|}
\hline $\begin{array}{c}\text { SI. } \\
\text { No }\end{array}$ & \multicolumn{1}{|c|}{ Selection traits } & \multicolumn{1}{|c|}{ Genotypes number } & \multicolumn{1}{|c|}{$\begin{array}{c}\text { Clustered } \\
\text { form }\end{array}$} & \multicolumn{1}{|c|}{$\begin{array}{c}\text { Mean } \\
\text { value }\end{array}$} \\
\hline I & Earliness (days) & PG001 & X & 80.39 \\
\hline 2 & Higher fruit length (cm) & PG001 & X & 11.27 \\
\hline 3 & Higher fruit width (cm) & $\begin{array}{l}\text { PG043, PG044, } \\
\text { PG045 and PG046 }\end{array}$ & IX & 3.76 \\
\hline 4 & $\begin{array}{l}\text { Higher fruit weight per plant } \\
\text { (Kg) }\end{array}$ & $\begin{array}{l}\text { PG023, PG029 and } \\
\text { PG042 }\end{array}$ & V & 12.51 \\
\hline 5 & $\begin{array}{l}\text { Higher number of fruits per } \\
\text { plant }\end{array}$ & $\begin{array}{l}\text { PGOO7. PG 0 l2 and } \\
\text { PGOI3 }\end{array}$ & II & 40 \\
\hline 6 & Number of lower seed & $\begin{array}{l}\text { PG023, PG029 and } \\
\text { PG042 }\end{array}$ & V & 19.36 \\
\hline 7 & Yield (t/ha) & $\begin{array}{l}\text { PG 023. PG029 and } \\
\text { PG042 }\end{array}$ & V & 37.45 \\
\hline
\end{tabular}




\section{References}

Mahalanobis, P.C. 1936. On the generalized distance in statistics. Proc. Nat. Inst. Sci. Ind., 2: 49-55.

Masud, M.A.T., M.A.Z. ChowdhLlry; M.A. Hossain and S.M.M. Hossain. 1995. Multivariate analysis in pumpkin (Cucurbita moschata Duch cx Poir). Bangladesh $J$. P1. Breed. Genet. 8(1 \&2): 45-50.

Mathew, S. M., P. K. Gopalakrishan and K. V. Peter. 1986. Genetic distance among five botanical varieties of Cucumis melo. Agric. Rcs. J. Kerala. 24(2): 195-196

Rashid, M. M. 1999. Vegetable Science (in Bangla). 1st ed., Bangla Academy, Dhaka. Bangladesh. pp. 333-336.

Ram, D. 2001. Non-hierarchical Euclidean cluster analysis in pointed gourd. Indian J. Hort. 58 (3): 264-268.

Rao, C.R. 1952. Advanced Statistical Methods in l3iornetrical Research. John Wiley and Sons, New York.

Rao, C. R. 1964. The use and interception of principal component analysis in applied research. Sankhya 22: 317-318.

Singh, R.K. and RD. Chaudhury. 1985. Biometrical methods of quantitative genetic analysis. Harayana J. Hort Sci., 12(1): 151-156. 